\title{
Characterization of microbial population of 'Alheira' (a traditional Portuguese fermented sausage) by PCR-DGGE and traditional cultural microbiological methods
}

\author{
H. Albano ${ }^{1}$, I. Henriques ${ }^{2}$, A. Correia ${ }^{2}$, T. Hogg ${ }^{1}$ and P. Teixeira ${ }^{1}$ \\ 1 Escola Superior de Biotecnologia, Universidade Católica Portuguesa, Porto, Portugal \\ 2 CESAM and Departamento de Biologia, Universidade de Aveiro, 3810-193 Aveiro, Portugal
}

\section{Keywords}

fermented sausages, fingerprint, lactic acid

bacteria, PCR-denaturing gradient gel

electrophoresis.

\section{Correspondence}

Paula Teixeira, Rua Dr. António Bernardino de Almeida, 4200-072 Porto, Portugal.

E-mail: pcteixeira@esb.ucp.pt

\begin{abstract}
Aims: This study evaluates the microbial ecology of 'Alheira' by traditional microbiological analysis and a PCR-denaturing gradient gel electrophoresis (DGGE) protocol.

Methods and Results: Total microbial DNA from 'Alheiras' was extracted directly from the products and subjected to PCR using Eubacterial primers for $16 \mathrm{~S}$ rDNA. The amplicons were separated by DGGE. The results demonstrated that different products of the same batch display identical profiles, whereas products from different batches of the same producer could display different DGGE profiles. 'Alheiras' from different producers were distinguishable based on the respective DGGE profiles. The obtained sequences from prevalent phylotypes affiliated with order Lactobacillales and order Bacillales and class Gammaproteobacteria. The same samples were subjected to traditional microbiological analysis. In both methods, lactic acid bacteria were dominant and were present together with other organisms, mainly members of the family Micrococcaceae.

Conclusions: The approach explored in this study allowed the description of the microbial community present in 'Alheira' in particular the diversity of lactic acid bacteria.

Significance and Impact of the Study: This can be useful for the microbiological characterization of traditional products in order to develop new methods of quality control capable of supporting a standardization of the processes, while preserving their typical traits.
\end{abstract}

\section{Introduction}

The microbiology of fermented sausages is complex. The type of microflora that develops is often closely related to the ripening technique utilized. The manufacture of fermented sausages has a long history in Portugal where there is a wide variety of typical preparations.

'Alheira' is a traditional fermented meat sausage typical of the North of Portugal (Trás-os-Montes). 'Alheira de Mirandela' is a much appreciated product and represents an important resource for this region where more than 500 tons are produced annually. 'Alheira de Mirandela' is in the process of name registration as 'Traditional Guaranteed Speciality'. The specific characteristics of the final product mainly arise from the raw materials employed, the agro-ecosystem of the area of production and the traditional technology of manufacture. 'Alheira de Mirandela' is produced from pork and poultry meat, lard and pork fat, wheat bread and olive oil. Ingredients are mixed with salt, garlic and spices until they form a paste which is then stuffed into natural or artificial casings (horseshoeshaped sausages approximately $15 \pm 60 \mathrm{~mm}$ long) and submitted to a smoking process, at low but uncontrolled temperature (generally $<40^{\circ} \mathrm{C}$ ) and uncontrolled humidity, for no longer than 8 days. The shelf life of 'Alheiras' is about 1 month if stored at $4^{\circ} \mathrm{C}$ in air or longer if the sausages are packed under vacuum or modified atmosphere. 'Alheiras' are cooked before consumption either 
by frying, grilling or boiling, according to regional traditions or consumer preferences. A wide variety of microorganisms has already been isolated from 'Alheiras' by traditional methods. These are mainly lactic acid bacteria (LAB), Micrococcaceae and some pathogens, such as Listeria spp., Salmonella and Staphylococcus aureus (Ferreira et al. 2006; Esteves et al. 2008).

Genetic fingerprinting techniques that use DNA, generated by polymerase chain reaction (PCR) procedures, applied DNA extracted directly from environmental samples, can be used to provide profiles representing the phylogenetic diversity of the microbial community in the environment being studied. This approach eliminates the necessity for traditional culture-dependent methods like selective cultivation and strain isolation, thereby negating the potential biases inherent in such procedures. Moreover, studies which have employed such direct analyses have repeatedly demonstrated considerable variance between cultivated and naturally occurring species, thereby dramatically altering the perception of the true microbial diversity present in various habitats (Head et al. 1998; Hugenholtz et al. 1998; Cocolin et al. 2002a). Denaturing gradient gel electrophoresis (DGGE) is perhaps the most commonly used among the nonculture-dependent fingerprinting techniques. It is based on the separation of PCR amplicons of the same size according to their different melting temperatures. PCR-DGGE of ribosomal DNA was introduced into microbial ecology by Muyzer et al. (1993). Despite the wide range of applications, this technique has been introduced into food microbiology no longer than 10 years. The great potential shown in analysing samples from natural environments without employing a culture-based isolation, has stimulated food microbiologists to investigate the suitability of PCRDGGE to study microbial fermentations in food and food-related ecosystems. In the last few years, several papers have been published reporting the use of DGGE for LAB strain identification (Cocolin et al. 2000; Ercolini et al. 2001a; Ogier et al. 2002), for the study of the ecology of fermented foods and the microbial changes in $\mathrm{LAB}$ populations during these food fermentations and to profile pathogens directly in food samples (Cocolin et al. 2002b). In particular, direct PCR amplification of different regions of the $16 \mathrm{~S}$ rRNA gene and subsequent analysis by DGGE has been used to study the ecology of the microbial processes involved in the production of Mexican fermented maize dough (ben Omar and Ampe 2000), Mozzarella cheese (Coppola et al. 2001), fermented sausages (Cocolin et al. 2001a,b, 2004; Fontana et al. 2005; Rantsiou et al. 2005; Aquilanti et al. 2007), malt whisky (van Beek and Priest 2002), artisanal Sicilian cheese (Randazzo et al. 2002), buffalo Mozzarella and Stilton cheese (Ercolini et al. 2001b, 2003) and sourdough
(Meroth et al. 2003). The use of DGGE in food microbiology was reviewed by Ercolini (2004).

In this work, the microbial ecology of 'Alheiras', produced in six different plants in North-East Portugal, was studied by using culture-dependent and -independent methods. 'Alheiras' were subjected to traditional microbiological analysis in order to enumerate specific bacterial groups. The aim of this study was also to evaluate if PCR-DGGE could be useful to identify specific motifs in the bacterial community profiles of these products. To accomplish this aim, DNA was extracted directly from the same samples and 16S DNA fragments were amplified by PCR, using 'universal' bacterial primers. DGGE analysis allowed fingerprinting of the microbial populations present in 'Alheira de Mirandela' and determination of the DNA sequence of relevant bands permitted the establishment of the phylogenetic affiliation of bacteria present.

\section{Materials and methods}

\section{Sampling}

'Alheiras' from six different producers (two or three batches of each), were purchased from retail stores, at storage time, during 2005. Samples were labelled as Ef, Tp, Tx, Gr, Ag and Am to represent the six different producers.

\section{Microbiological analyses by cultural methods}

Samples of 'Alheiras' (25 g) were added to $225 \mathrm{ml}$ of sterile buffered peptone water (Merck, Darmstadt, Germany), and homogenized in a stomacher for $2 \mathrm{~min}$. Appropriate decimal dilutions were prepared in sterile Ringer's solution (LabM, Bury, UK) for microbial enumeration: LAB on de Man, Rogosa Sharpe Agar (MRS, LabM) and on M17 (LabM), incubated at $30^{\circ} \mathrm{C}$ for $72 \mathrm{~h}$; total counts at $30^{\circ} \mathrm{C}$ according to ISO Standard 4833 (ISO 2003); Enterococcaceae on bile esculin azide agar (Biokar Diagnostics, Beauvais, France), incubated at $30^{\circ} \mathrm{C}$ for $72 \mathrm{~h}$; Micrococcaceae on mannitol salt agar (Biokar Diagnostics), incubated at $37^{\circ} \mathrm{C}$ for $48 \mathrm{~h}$; Enterobacteriaceae according to the Portuguese Standard NP 4137 (IPQ 1991). Enumeration of Listeria spp. was performed on Palcam Agar (Merck) medium and incubated at $30^{\circ} \mathrm{C}$ for $72 \mathrm{~h}$. Three independent analyses, using randomly selected pieces, were performed for each sample.

\section{DNA extraction}

Ten grams samples were homogenized in a stomacher bag with $10 \mathrm{ml}$ of saline-peptone water for $1 \mathrm{~min}$. After each preparation had settled for $1 \mathrm{~min}, 1 \mathrm{ml}$ subsamples were 
placed in $1 \cdot 5-\mathrm{ml}$ screw-cap tubes containing $0 \cdot 3 \mathrm{~g}$ of glass beads. Total DNA was extracted from 'Alheira' following the method previously described for fermented sausages (Cocolin et al. 2001a), using treatment with vortex instead bead beader.

\section{PCR-DGGE protocol}

DNA was amplified with primers 338F (5'-GACTCCTACGGGAGGCAGCAG-3') and 518R (5'-ATTACCGCGGCTGCTGG-3'), with a GC clamp attached to the forward primer (5), spanning the V3 region of the bacterial 16S rRNA gene (Muyzer et al. 1993). PCR was performed in a Bio-Rad iCycler Thermal Cycler (Bio-Rad Laboratories, Hercules, CA, USA) as previously described (Henriques et al. 2006). Five microlitres of the product was analysed by standard agarose gel electrophoresis before DGGE analysis.

DGGE was performed on a DCode ${ }^{\mathrm{TM}}$ Universal Mutation Detection System (Bio-Rad Laboratories), according to Henriques et al. (2006). Briefly, samples were loaded onto $8 \%$ polyacrylamide gels $(37 \cdot 5: 1$, acrylamide: bisacrylamide $)$ in $0.5 \mathrm{x}$ TAE buffer $\left(20 \mathrm{mmol} \mathrm{l}^{-1}\right.$ Tris-acetate, $\mathrm{pH} \quad 7 \cdot 4, \quad 10 \mathrm{mmol} \mathrm{l}^{-1}$ sodium acetate, $0.5 \mathrm{mmol} \mathrm{l}^{-1}$ $\mathrm{Na}_{2}$ EDTA) using a denaturing gradient ranging from 35 $50 \%$ (100\% denaturant contains $7 \mathrm{~mol} \mathrm{l}^{-1}$ urea and 40\% formamide). Electrophoresis was performed at $60^{\circ} \mathrm{C}$, initially at $20 \mathrm{~V}(15 \mathrm{~min})$ and then at $200 \mathrm{~V}(330 \mathrm{~min})$. The gels were stained in an ethidium bromide solution $(5 \mathrm{~min})$ and then rinsed in distilled water $(20 \mathrm{~min})$. The image was acquired using a Molecular Image FX apparatus (Bio-Rad Laboratories). Every gel contained two lanes with a standard of eight bands for internal and external normalization and as an indication of the quality of the analysis.

\section{Sequencing of DGGE bands and phylogenetic analysis}

DGGE bands were excised with a sterile scalpel and eluted in $20 \mu \mathrm{l}$ of sterile water, overnight at $4^{\circ} \mathrm{C}$. Five microlitres of the supernatant was used for re-amplification with the original primer set. The accuracy of the bands and the position in the gel were checked on DGGE gels together with the original sample. Whenever necessary, bands were processed again as described above.

For sequencing analysis, PCR products were purified with the Jetquick PCR Purification Spin Kit (Genomed, Löhne, Germany) and used as template in the sequencing reactions. Those were carried out using the primer 518R and an ABI Prism ${ }^{\circledR}$ BigDye ${ }^{\mathrm{TM}}$ Terminator Cycle Sequencing Ready Reaction Kit (PE Applied Biosystems, Foster City, CA, USA). The reaction mixtures were analysed in an automatic DNA sequencer (ABI Prism ${ }^{\circledR} 310$ Genetic Analyzer, PE Applied Biosystems).
Band sequences were compared to the GenBank nucleotide data library using the BLAST software at the National Center of Biotechnology Information website (http://www.ncbi.nlm.nih.gov/) in order to determine their closest phylogenetic relatives.

\section{Nucleotide sequence accession numbers}

The nucleotide sequences determined in the present study have been deposited in the GenBank database under the accession numbers EU555489-EU555518.

\section{Results}

'Alheiras' from six different producers, named Gr, Am, Ef, Tx, Ag and Tp (Fig. 1), were sampled during retail display at storage time from retail stores. From each producer, two or three batches (' 1 ', ' 2 ' and ' 3 ' in Fig. 1) were used and, from each batch, two replicates were taken (' $a$ ' and ' $b$ ' in Fig. 1 correspond to the same batch). 'Alheiras' were subjected to traditional microbiological analysis and DNA, directly extracted from the samples, was subjected to DGGE analysis from which dominant bands were sequenced.

\section{Microbiological characterization by cultural methods}

The results of the plate counts obtained from the six producers and their samples in this study are reported in Table 1. It is clear that there is variability in counts between producers and even between different lots from the same producer. The values of total counts at $30^{\circ} \mathrm{C}$ were greater than $8.7 \mathrm{log}_{\mathrm{CFU} \mathrm{g}}{ }^{-1}$ in most samples with LAB being the dominant microflora. Counts on MRS and M17 were, in most cases, $>7.5 \log \mathrm{CFU} \mathrm{g}{ }^{-1}$, with the exception of one sample from producer Gr (Table 1). In addition, enterococci counts were $>6.5 \log \mathrm{CFU} \mathrm{g}^{-1}$ in most samples. With the exception of one of the samples from producers $\mathrm{Gr}$, Ef and Tx, counts on mannitol salt agar were $>\log 4 \cdot 44 \log \mathrm{CFU} \mathrm{g}{ }^{-1}$, although values varied between $4 \cdot 4 \log \mathrm{CFU} \mathrm{g}^{-1}$ and $>6 \cdot 20 \log _{\mathrm{CFU} \mathrm{g}}{ }^{-1}$. Enterobacteriaceae counts were $>4 \log \mathrm{CFU} \mathrm{g}^{-1}$ in most samples, with the exception of producer Gr. Listeria spp. was isolated in countable quantities in some samples, the highest values coming from two samples from the producer $\mathrm{Tx}$ (3.8 $\mathrm{CFU} \mathrm{g}^{-1}$ and $\left.4 \cdot 3 \mathrm{CFU} \mathrm{g}^{-1}\right)$.

\section{DGGE analysis}

A sample-specific fingerprint was obtained from total DNA directly extracted from 'Alheiras', after amplification of the V3 region of 16S rRNA gene followed by DGGE analysis (Fig. 1). Reproducibility of PCR amplification 


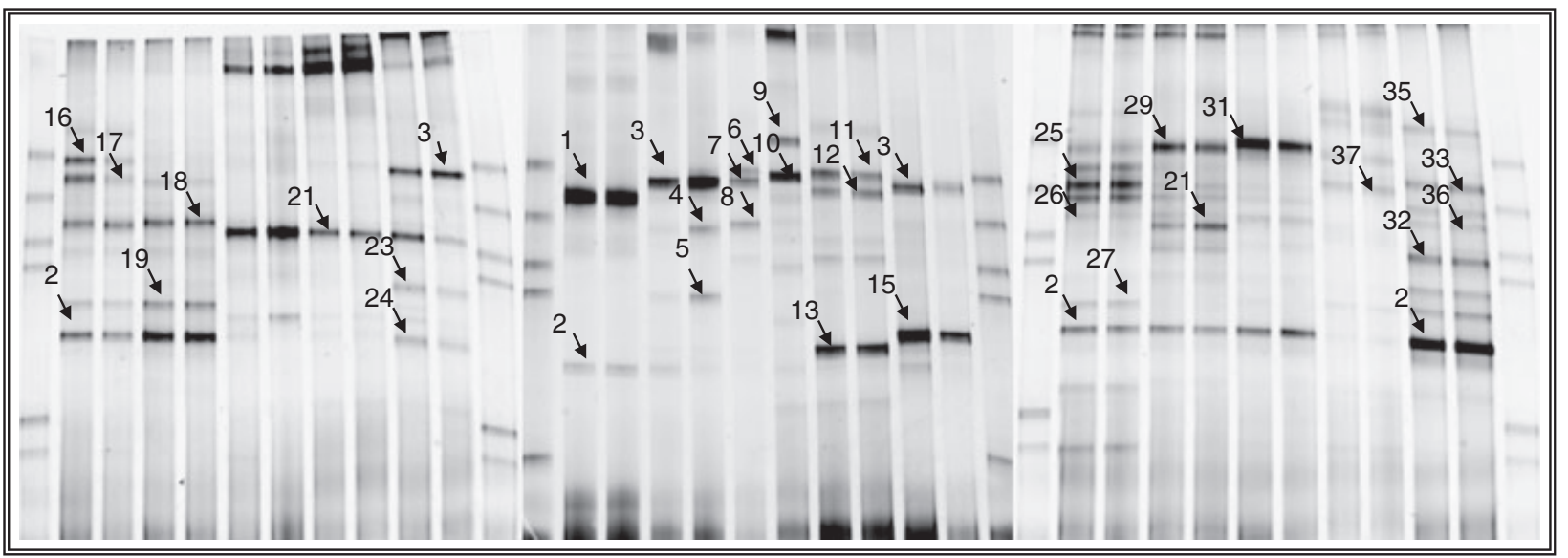

Figure 1 DGGE gels showing PCR-amplified bacterial 16S rRNA gene profiles from 'Alheiras' from six different producers (Ag, Am, Ef, Gr, Tp, Tx; $a$ and b correspond to the same batch; indicated on top of the lanes). Lane M: DGGE marker constructed using previously characterized 16S rRNA gene clones from environmental libraries (Henriques et al. 2004). Bands that were excised for sequence analysis are labelled with the same number as in Table 2 and indicated with an arrow.

and DGGE was confirmed by performing three replicate runs, the profiles proving to be highly reproducible between different gels and PCR runs. The total number of band positions detected in the three gels was 30 and the number of DGGE bands per sample varied between 2 and 10 indicating significant differences between samples in terms of their microbial diversity. Samples Gr1, Am3, $\mathrm{Tx} 2, \mathrm{Ag} 1$ and $\mathrm{Tp} 2$ displayed the most complex profiles, whereas samples Am1, Am2, Ef1 and Ef3 displayed simpler profiles.

In general, products from the same batch displayed identical profiles, with the exception of sample Tx1, where products from the same batch displayed different DGGE profiles. On the other hand, for some producers, consistent profiles were evident within different batches of 'Alheira'; certainly this was the case for producers Gr, Am, Ag and Tx. Producers Ef and Tp produced batches which were much less consistent in terms of the microbial ecology present.

\section{Sequencing and identification of DGGE fragments}

Thirty-one bands were excised from the three DGGE gels and re-amplified with the primers $338 \mathrm{~F}$ and $518 \mathrm{R}$

Table 1 Microbiological characterization of 'Alheira de Mirandela' from six different producers (Ag, Am, Ef, Gr, Tp, Tx;): important microbial parameters in fermented products

\begin{tabular}{|c|c|c|c|c|c|c|c|}
\hline Producer & $\begin{array}{l}\text { Total counts } \\
30^{\circ} \mathrm{C}(\log \mathrm{CFU} \mathrm{g} \\
\end{array}$ & $\begin{array}{l}\text { Counts on } \\
\text { MRS }\left(\log \text { CFU g }{ }^{-1}\right)\end{array}$ & $\begin{array}{l}\text { Counts on M17 } \\
\left(\log C F U g^{-1}\right)\end{array}$ & $\begin{array}{l}\text { Counts on MSA } \\
\left(\log C F U g^{-1}\right)\end{array}$ & $\begin{array}{l}\text { Enterococci } \\
\left(\log C F U g^{-1}\right)\end{array}$ & $\begin{array}{l}\text { Enterobacteria } \\
\left(\log \text { CFU g }{ }^{-1}\right)\end{array}$ & $\begin{array}{l}\text { Listeria spp. } \\
\left(\log C F U g^{-1}\right)\end{array}$ \\
\hline Gr1 & $6.9 \pm 0.6$ & $6 \cdot 0 \pm 0.0$ & $6 \cdot 0 \pm 0.3$ & $5 \cdot 4 \pm 0.2$ & $7 \cdot 7 \pm 0.3$ & $2 \cdot 3 \pm 0 \cdot 1$ & $<1$ \\
\hline Gr2 & $9 \cdot 7 \pm 0 \cdot 2$ & $8.8 \pm 0.6$ & $8 \cdot 8 \pm 0 \cdot 2$ & $<1$ & $6 \cdot 6 \pm 0.0$ & $2 \cdot 7 \pm 0.3$ & $1 \cdot 2 \pm 0 \cdot 2$ \\
\hline Am1 & $9 \cdot 4 \pm 0 \cdot 3$ & $8 \cdot 6 \pm 0.1$ & $9 \cdot 0 \pm 0.8$ & $>6 \cdot 2 \pm 0 \cdot 3$ & $9 \cdot 3 \pm 0 \cdot 2$ & $7 \cdot 1 \pm 0 \cdot 0$ & $<1$ \\
\hline Am2 & $1 \cdot 0 \pm 0.2$ & $8 \cdot 8 \pm 0.2$ & $8.5 \pm 0.2$ & $4 \cdot 4 \pm 0 \cdot 6$ & $7 \cdot 8 \pm 0.5$ & $6 \cdot 3 \pm 0.0$ & $<1$ \\
\hline Am3 & $9 \cdot 7 \pm 0 \cdot 1$ & $8.5 \pm 0.1$ & $7 \cdot 9 \pm 0 \cdot 1$ & $4 \cdot 2 \pm 0 \cdot 0$ & $7 \cdot 2 \pm 0 \cdot 1$ & $6 \cdot 8 \pm 0 \cdot 2$ & $2 \cdot 3 \pm 0 \cdot 3$ \\
\hline Ef1 & $9 \cdot 6 \pm 0.2$ & $7 \cdot 6 \pm 0 \cdot 8$ & $7 \cdot 7 \pm 0 \cdot 1$ & $<1$ & $4.6 \pm 0.2$ & $3 \cdot 3 \pm 0.2$ & $<1$ \\
\hline Ef2 & $8.7 \pm 0.4$ & $7 \cdot 7 \pm 0 \cdot 1$ & $7 \cdot 9 \pm 0.4$ & $5 \cdot 9 \pm 0 \cdot 1$ & $7 \cdot 0 \pm 0.0$ & $5 \cdot 6 \pm 0 \cdot 3$ & $<1$ \\
\hline$T \times 1$ & $9.5 \pm 0.0$ & $9 \cdot 8 \pm 0 \cdot 2$ & $9 \cdot 8 \pm 0 \cdot 3$ & $6 \cdot 0 \pm 0 \cdot 0$ & $7 \cdot 1 \pm 0 \cdot 1$ & $4 \cdot 2 \pm 0 \cdot 3$ & $3 \cdot 7 \pm 0 \cdot 1$ \\
\hline$T \times 2$ & $9 \cdot 4 \pm 0.3$ & $8 \cdot 1 \pm 0 \cdot 3$ & $9 \cdot 4 \pm 0 \cdot 2$ & $>6 \cdot 2$ & $>7 \cdot 2$ & $4 \cdot 3 \pm 0.8$ & $<1$ \\
\hline$T \times 3$ & $9 \cdot 3 \pm 0 \cdot 2$ & $8 \cdot 0 \pm 0 \cdot 2$ & $9 \cdot 1 \pm 0 \cdot 2$ & $<1$ & $7 \cdot 4 \pm 0 \cdot 0$ & $7 \cdot 2 \pm 0 \cdot 2$ & $4 \cdot 3 \pm 0 \cdot 2$ \\
\hline Ag1 & $9 \cdot 8 \pm 0 \cdot 1$ & $8.9 \pm 0.1$ & $8 \cdot 9 \pm 0.1$ & $5 \cdot 8 \pm 0 \cdot 0$ & $>7 \cdot 2$ & $>7 \cdot 5$ & $<1$ \\
\hline Ag2 & $>10.5$ & $9 \cdot 8 \pm 0 \cdot 5$ & $>10 \cdot 5$ & $>6 \cdot 2$ & $>7 \cdot 2$ & $6.9 \pm 0.4$ & $<1$ \\
\hline Ag3 & $10 \cdot 4 \pm 0 \cdot 1$ & $9 \cdot 9 \pm 0 \cdot 3$ & $>10 \cdot 5$ & $5 \cdot 9 \pm 0 \cdot 1$ & $6 \cdot 8 \pm 0 \cdot 3$ & $4.9 \pm 0.2$ & $<1$ \\
\hline Tp1 & $10 \cdot 4 \pm 0 \cdot 4$ & $9 \cdot 2 \pm 0 \cdot 0$ & $9 \cdot 0 \pm 0 \cdot 1$ & $>6 \cdot 2$ & $>7 \cdot 2$ & $>7 \cdot 5$ & $<1$ \\
\hline Tp2 & $9 \cdot 5 \pm 0 \cdot 1$ & $8 \cdot 0 \pm 0 \cdot 1$ & $7 \cdot 7 \pm 0 \cdot 0$ & $5 \cdot 9 \pm 0 \cdot 2$ & $6 \cdot 4 \pm 0.2$ & $5 \cdot 5 \pm 0.0$ & $2 \cdot 4 \pm 0 \cdot 3$ \\
\hline
\end{tabular}


Table 2 Closest relatives of DGGE band sequences

\begin{tabular}{|c|c|c|c|c|}
\hline Band no. & Accession number & Sample & Closest relative (accession number) & Similarity (\%) \\
\hline 1 & EU555489 & Ef1a & Lactobacillus sakei (EU081017.1) & 100 \\
\hline 2 & EU555490 & Ef1a & Brochothrix thermosphacta (AY543029.1) & 100 \\
\hline 3 & EU555491 & Ef2a & Leuconostoc lactis (AB295117.1) & 98 \\
\hline 4 & EU555492 & $E f 2 b$ & Streptococcus lutetiensis (EU163503) & 100 \\
\hline 5 & EU555493 & $E f 2 b$ & Macrococcus caseolyticus (EU048336.1) & 100 \\
\hline 6 & EU555494 & Tx1a & Uncultured soil bacterium clone (EU052112.1) & 100 \\
\hline 7 & EU555495 & Tx1a & Lactococcus lactis (EU080989.1) & 99 \\
\hline 8 & EU555496 & Tx1a & Pseudomonas sp. (EF028699.1) & 99 \\
\hline 9 & EU555497 & $T \times 1 b$ & Leuconostoc mesenteroides (EU099617.1) & 99 \\
\hline 10 & EU555498 & $\mathrm{Tx} 1 \mathrm{~b}$ & Weissella paramesenteroides (EF422380.1) & 100 \\
\hline 11 & EU555499 & $T \times 2 b$ & Enterococcus sp.(EU157915) & 100 \\
\hline 12 & EU555500 & $T \times 2 b$ & Enterococcus gallinarum (EF025908) & 98 \\
\hline 13 & EU555501 & $T \times 2 a$ & Pediococcus acidilactici (EF059987.1) & 100 \\
\hline 15 & EU555502 & Tx3a & Lactococcus lactis BMG 125 (EU080989.1) & 99 \\
\hline 16 & EU555503 & Gr1a & Uncultured Bacilli bacterium (EF706149.1) & 100 \\
\hline 17 & EU555504 & Gr1b & Pseudomonas aeruginosa (DQ149582.1) & 99 \\
\hline 18 & EU555505 & Gr2b & Psychrobacter sp. (EU075120.1) & 100 \\
\hline 19 & EU555506 & Gr2a & Acinetobacter sp. (AB365066) & 100 \\
\hline 21 & EU555507 & Am2a & Uncultured bacterium DGGE gel band (EU200335) & 100 \\
\hline 23 & EU555508 & Am3a & Uncultured bacterium (AY511592.1) & 99 \\
\hline 24 & EU555509 & Am3a & Klebsiella sp. (EU075144.1) & 99 \\
\hline 25 & EU555510 & Ag1a & Lactobacillus curvatus (EU081014.1) & 100 \\
\hline 26 & EU555511 & Ag1a & Bacillus sp. (DQ448756.1) & 98 \\
\hline 27 & EU555512 & Ag1b & Psychrobacter sp. (AJ582399.1) & 99 \\
\hline 29 & EU555513 & Ag2a & Lactobacillus brevis (EF120367.1) & 98 \\
\hline 31 & EU555514 & Ag3a & Uncultured Bacilli bacterium (EF706149.1) & 98 \\
\hline 32 & EU555515 & Tp2a & Uncultured soil bacterium clone G08 (EU052112.1) & 99 \\
\hline 35 & EU555516 & Tp2a & Hafnia alvei strain (AM042710.1) & 99 \\
\hline 36 & EU555517 & Tp2b & Uncultured Bacilli bacterium (EF706149.1) & 100 \\
\hline 37 & EU555518 & Tp1b & Lactobacillus curvatus (EU081014.1) & 100 \\
\hline
\end{tabular}

(Table 2). Figure 1 shows the original gel from which the bands were excised together with band numbers. The sequence obtained from band 33 was of low quality and so not considered for phylogenetic analysis.

In Table 2 the closest relatives of DGGE band sequences is presented. In some cases retrieved sequences shared the same value of similarity with several closely related micro-organisms and in such cases only one example of each close relative is presented.

Most of the sequences were similar to 16S rRNA gene sequences reported for cultured bacteria present in food samples such as meat products, packaged fish, spoiled food, fermented vegetables and cheese (Table 2). However, the DNA sequence of some bands affiliated to sequences with their origins in bacteria initially isolated from other sources such as soil, marine sediments, human blood, phyllosphere, animal gut, faeces and ice. Six bands (labelled in Fig. 1 as 6, 16, 21, 23, 31, 32 and 36) affiliated with sequences corresponding to bacteria classified as 'uncultured' in the BLAST database. In the case of DNA sequences from bands 6 and 32, these could not be clearly affiliated to any phylogenetic group, displaying similarity with 16S rRNA gene sequences from uncultured bacterial clones.

According to BLAST results sequences affiliated with LAB, included in order Lactobacillales, with micro-organisms included in order Bacillales and with Gammaproteobacteria. Most of the profiles displayed clearly dominant bands (Fig. 1). Bands affiliated with Lactobacillus were found in samples from producers $\mathrm{Ef}, \mathrm{Ag}$ and $\mathrm{Tp}$; bands affiliated with Leuconostoc were found in producers Ef, Am and Tx (Band 3); Enterococcus were found only in samples form producer $\mathrm{Tx}$; samples from producer $\mathrm{Am}$ have an intense band affiliated with Firmicutes (Band 21); samples form producer Tx have intense bands affiliated with Pediococcus and Lactococcus (Band 13 and 15, Fig. 1); band associated with Psychrobacter is intense in producer Gr. Band 2 was detected at the same position in all the six producers. To confirm that matching positions correspond to identical phylotypes, Band 2 was excised and sequenced from all samples. The same nucleotide sequence was obtained for each band. This band position was detected in most of the profiles (exceptions were samples Am3a and Am3b), although it was more 
pronounced in samples Gr2a, Gr2b, Tp2a and Tp2b. The sequence from this band was $100 \%$ identical to Brochothrix thermosphacta, isolated from modified-atmospherepacked salmon and coalfish. In addition, Bands 7 and 15 were retrieved from different gels as presented in Fig. 1 and confirmed as identical.

\section{Discussion}

Studies on the micro-ecology of fermented sausages date back to the 1970s (Lücke 1974). These earlier studies, based on traditional methods, described the microbial populations developing during production and storage. In the last few years, the possibility of using cultureindependent molecular approaches has opened up areas of research. In this study we used PCR-DGGE analyses in combination with traditional microbiological analyses for studying the microbial diversity of 'Alheira'. Microbial DNA was sampled directly in order to determine the diversity of the 16S rRNA genes of the most prominent bacteria, which may also reflect the microflora of 'Alheira'.

The most salient observation from Fig. 1 concerns the variability in the microecology between samples from different producers, which is considerable, and that between lots from the same producer which is evident but lesser. Variability between producers is not, in itself, surprising; production methods, recipes and raw materials vary themselves. Other factors probably contributing to the detected inter-producer variability include the manner in which they were stored and distributed ('Alheiras' are sold loose or packaged - vacuum or modified atmosphere) and indeed the time elapsed since production not all samples were labelled with shelf life information. Indeed, as a largely artisanal production process which is not initiated by starter cultures, these same factors are likely to be responsible for the intra-producer variations. The variations between batches from the same producer are less pronounced which suggests some stability of the microecology although variations in batches of raw materials, process parameters and plant hygiene are likely to contribute some variation.

When the results obtained from both traditional plating and DGGE are analysed (Tables 1 and 2), it becomes evident that $\mathrm{LAB}$ constitute the predominant microbial population of 'Alheira'. In DGGE gels, multiple bands were visible in most of the samples, and different phylotypes, most of which related to the order Lactobacillales, were identified. In a previous, culture-based study, fourteen species of LAB were isolated from 'Alheira' from MRS and M17 media, such us: Lact. paraplantarum, Lact. brevis, Lact. rhamnosus, Lact. sakei, Leuc. mesenteroides, Lact. zeae, Lact. paracasei, Ped. pentosaceus, Ped. acidilactici, Weissella cibaria, W. viridescens and Ent. faecium
(Albano et al. 2007). Albano et al. (2007) also observed that Lact. plantarum and members of the genus Enterococcus were isolated from all samples of 'Alheira' analysed. Enterococcus-related phylotypes were identified also in PCR-DGGE sequences.

In addition to LAB, Micrococcaceae counts were $>4.2 \log \mathrm{CFU} \mathrm{g}^{-1}$ in most samples. Intriguingly, although the separation of the V1 and V3 rRNA gene amplicons by PCR-DGGE has been described as a reliable tool to investigate the $\mathrm{LAB}$ and $\mathrm{CNC}$ diversity in fermented sausages (Cocolin et al. 2001a,b), only one band was identified as being part of this latter microbial group (Macrococcus caseolyticus, Band 5) in the denaturing gels generated in this present study. This finding might be due to the selective amplification of the most abundant templates, a bias previously recognized when performing PCR-DGGE analysis of heterogeneous DNA template mixtures (Felske et al. 1998; Ampe et al. 1999; Ercolini et al. 2001b).

According to the guidelines for the microbiological quality of fermented meats published by Gilbert et al. (2000), most of the samples tested (80\%) would be considered unsatisfactory, with Enterobacteriaceae counts greater than $4 \log \mathrm{CFU} \mathrm{g}^{-1}$. The detection of Listeria spp. in some samples points to the possibility of product contamination with the pathogenic specie L. monocytogenes. Sequences closely related to Enterobacteriaceae were retrieved from DGGE bands. Brochothrix-related phylotypes were also detected in almost all the samples, as were close relatives of Pseudomonas; in both cases suggesting the presence of potential spoilage strains. Quantitative approaches, such as those using real-time PCR would be needed in order to quantify the presence of specific potentially problematic bacteria. As shown by Rantsiou and Cocolin (2006), the combination of cultivation strategies and DNA-based techniques allows the identification of the dominant microbial species in fermented sausages, since it permits the generation and comparison of characteristic patterns from cultivated isolates and complex microbial communities. However, Ercolini (2004) described possible pitfalls of the whole procedure when applied to food products, like sampling, DNA extraction, DNA purity, PCR conditions, formation of heteroduplex and chimeric molecules, small fragments, between others.

PCR-DGGE applied to template DNA, directly extracted from a food matrix, generates a specific profile of that product in that moment, given the conditions used. DGGE analysis and sequencing of the resultant bands allows the identification of the dominant phylotypes present in all products. The approach explored in this study allowed the description of the microbial community present in 'Alheira' in particular the diversity of LAB. DGGE could be used in monitoring the growth kinetics during the ripening process and the effects of 
these on the hygienic quality, allowing tracking of the microbial 'typicity' of the 'Alheira de Mirandela', and collecting of important information for the designing of autochthonous starter cultures.

\section{Acknowledgements}

This work received financial support via project POCTI/ AGG/39587/2001, Fundação para a Ciência e Tecnologia (FCT)/Fundo Europeu Desenvolvimento Regional (FEDER). Financial support for author H. Albano was provided by $\mathrm{PhD}$ fellowship, SFRH/BD/13161/2003 (FCT) and for I. Henriques by $\mathrm{PhD}$ fellowship (SFRH/BPD/ 21384/2005).

\section{References}

Albano, H., van Reenen, C.A., Todorov, S.D., Hogg, T., Dicks, L.M.T. and Teixeira, P. (2007) Ecology of lactic acid bacteria in "Alheira", a fermented sausage traditionally produced in Portugal: isolation, identification and molecular characterization. Personal communication in MICRO'07 BIOTEC'07-XXXIII, Lisbon, Portugal, 30 November, 2007-2 December, 2007.

Ampe, F., ben Omar, N., Moizan, C., Wacher, C. and Guyot, J.-P. (1999) Polyphasic study of the spatial distribution of microorganisms in Mexican pozol, a fermented maize dough, demonstrates the need for cultivation independent methods to investigate traditional fermentations. Appl Environ Microbiol 65, 5464-5473.

Aquilanti, L., Santarelli, S., Silvestri, G., Osimani, A., Petruzzelli, A. and Clementi, F. (2007) The microbial ecology of a typical Italian salami during its natural fermentation. Int J Food Microbiol 120, 136-145.

van Beek, S. and Priest, F.G. (2002) Evolution of the lactic acid bacterial community during malt whisky fermentation: a polyphasic study. Appl Environ Microbiol 68, 297-305.

Cocolin, L., Manzano, M., Cantoni, C. and Comi, G. (2000) Development of a rapid method for the identification of Lactobacillus spp. isolated from naturally fermented Italian sausages using a polymerase chain reaction-temperature gradient gel electrophoresis. Lett Appl Microbiol 30, $126-129$.

Cocolin, L., Manzano, M., Cantoni, C. and Comi, G. (2001a) Denaturing gradient gel electrophoresis analysis of the $16 \mathrm{~S}$ rRNA gene V1 region to monitor dynamic changes in the bacterial population during fermentation of Italian sausages. Appl Environ Microbiol 67, 5113-5121.

Cocolin, L., Manzano, M., Aggio, D., Cantoni, C. and Comi, G. (2001b) A novel polymerase chain reaction (PCR) denaturing gradient gel electrophoresis (DGGE) for the identifcation of Micrococcaceae strains involved in meat fermentations. Its application to naturally fermented Italian sausages. Meat Sci 57, 59-64.
Cocolin, L., Aggio, D., Manzano, M., Cantoni, C. and Comi, G. (2002a) An application of PCR-DGGE analysis to profile the yeast populations in raw milk. Int Dairy J 12, 407-411.

Cocolin, L., Rantsiou, K., Iacumin, L., Cantoni, C. and Comi, G. (2002b) Direct identification in food samples of Listeria spp. and Listeria monocytogenes by molecular methods. Appl Environ Microbiol 68, 6273-6282.

Cocolin, L., Rantsiou, K., Iacumin, L., Urso, R., Cantoni, C. and Comi, G. (2004) Study of the ecology of fresh sausages and characterization of populations of lactic acid bacteria by molecular methods. Appl Environ Microbiol 70, 1883-1894.

Coppola, S., Blaiotta, G., Ercolini, D. and Moschetti, G. (2001) Molecular evaluation of microbial diversity occurring in different types of Mozzarella cheese. J Appl Microbiol 90, 414-420.

Ercolini, D. (2004) PCR-DGGE fingerprinting: novel strategies for detection of microbes in food. J Microbiol Methods 56, 297-314.

Ercolini, D., Moschetti, G., Blaiotta, G. and Coppola, S. (2001a) Behavior of variable V3 region from 16S rDNA of lactic acid bacteria in denaturing gradient gel electrophoresis. Curr Microbiol 42, 199-202.

Ercolini, D., Moschetti, G., Blaiotta, G. and Coppola, S. (2001b) The potential of a polyphasic PCR-DGGE approach in evaluating microbial diversity of natural whey cultures for water-buffalo mozzarella cheese production: bias of "culture dependent" and "culture independent" approaches. Syst Appl Microbiol 24, 610-617.

Ercolini, D., Hill, P.J. and Dodd, C.E.R. (2003) Bacterial community structure and location in Stilton cheese. Appl Environ Microbiol 69, 3540-3548.

Esteves, A., Patarata, L., Saraiva, C. and Martins, C. (2008) Assessment of the microbiological characteristics of industrially produced Alheira, with particular reference to foodborn pathogens. J Food Safety 28, 88-102.

Felske, A., Akkermans, A.D. and de Vos, W.M. (1998) Quantification of $16 \mathrm{~S}$ rRNAs in complex bacterial communities by multiple competitive reverse transcription-PCR in temperature gradient gel electrophoresis fingerprints. Appl Environ Microbiol 64, 4581-4587.

Ferreira, V., Barbosa, J., Vendeiro, S., Mota, A., Silva, F., Monteiro, M.J., Hogg, T., Gibbs, P. et al. (2006) Chemical and microbiological characterization of alheira: a typical Portuguese fermented sausage with particular reference to factors relating to food safety. Meat Sci 73, 570-575.

Fontana, C., Vignolo, G. and Cocconcelli, P.S. (2005) PCRDGGE analysis for the identification of microbial populations from Argentinean dry fermented sausages. J Microbiol Methods 63, 254-263.

Gilbert, R.J., de Louvois, J., Donovan, T., Little, C., Nye, K., Ribeiro, C.D., Richards, J. and Roberts, D. (2000) Guidelines for the microbiological quality of some ready-to-eat foods sampled at the point of sale. PHLS advisory 
committee for food and dairy products. Communicable Dis Public Health 3, 163-167.

Head, I.M., Saunders, J.R. and Pickup, R.W. (1998) Microbial evolution, diversity and ecology: a decade of ribosomal RNA analysis of uncultivated microorganisms. Microbiol Ecol 35, 1-21.

Henriques, I.S., Almeida, A., Cunha, A. and Correia, A. (2004) Molecular sequence analysis of prokaryotic diversity in the middle and outer sections of the Portuguese estuary Ria de Aveiro. FEMS Microbiol Ecol 49, 269-279.

Henriques, I.S., Alves, A., Tacão, M., Almeida, A., Cunha, A. and Correia, A. (2006) Seasonal and spatial variability of free-living bacterial community composition along an estuarine gradient (Ria de Aveiro, Portugal). Estuar Coast Shelf Sci 68, 139-148.

Hugenholtz, P., Goebel, B.M. and Pace, N.R. (1998) Impact of culture-independent studies on emerging phylogenetic view of bacterial diversity. J Bacteriol 180, 4765-4774.

IPQ (1991) Food Microbiology. General Guidance for the Enumeration of Enterobacteriacea Without Ressuscitation. MPN Technique and Colony Count Technique. Portuguese Standard NP 4137.

ISO (2003) Microbioloy of Food and Animal Feeding Stuffs Horizontal Method for the Enumeration of Microorganisms Colony-Count Technique at $30^{\circ} \mathrm{C}$. International Standard 4833:2003E.

Lücke, F.K. (1974) Fermented sausages. In Microbiology of Fermented Foods ed. Wood, B.J.B. pp. 41-49 London: Applied Science Publishers.

Meroth, C.B., Walter, J., Hertel, C., Brandt, M.J. and Hammes, W.P. (2003) Monitoring the bacterial population dynamics in sourdough fermentation process by using PCR-denaturing gradient gel electrophoresis. Appl Environ Microbiol 69, 475-482.

Muyzer, G., De Waal, E.D. and Uitterlinden, A.G. (1993)

Profiling of complex microbial populations by denaturing gradient gel electrophoresis analysis of polymerase chain reaction-amplified genes coding for 16S rRNA. Appl Environ Microbiol 59, 695-700.

Ogier, J.C., Son, O., Gruss, A., Tailliez, P. and DelacroixBuchet, A. (2002) Identification of the bacterial microflora in dairy products by temporal temperature gradient gel electrophoresis. Appl Environ Microbiol 68, 3691-3701.

ben Omar, N. and Ampe, F. (2000) Microbial community dynamics during production of the Mexican fermented maize dough pozol. Appl Environ Microbiol 66, 36643673.

Randazzo, C.L., Torriani, S., Akkermans, A.D.L., de Vos, W.M. and Vaughan, E.E. (2002) Diversity, dynamics, and activity of bacterial communities during production of an artisanal Sicilian cheese as evaluated by $16 \mathrm{~S}$ rRNA analysis. Appl Environ Microbiol 68, 1882-1892.

Rantsiou, K. and Cocolin, L. (2006) New developments in the study of the microbiota of naturally fermented sausages as determined by molecular methods: a review. Int J Food Microbiol 108, 255-267.

Rantsiou, K., Urso, R., Iacumin, L., Cantoni, C., Cattaneo, P., Comi, G. and Cocolin, L. (2005) Culture-dependent and -independent methods to investigate the microbial ecology of Italian fermented sausages. Appl Environ Microbiol 71, 1977-1986. 